\title{
Numerical simulation of coal wall cutting and lump coal formation in a fully mechanized mining face
}

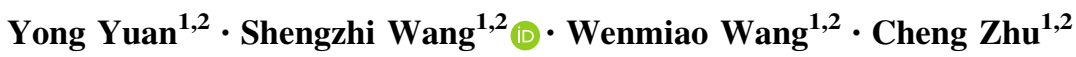

Received: 3 August 2020/Revised: 13 September 2020/Accepted: 23 December 2020/Published online: 23 January 2021

(C) The Author(s) 2021

\begin{abstract}
It is difficult to accurately calculate the lump coal rate in a fully mechanized mining face. Therefore, a numerical simulation of the coal wall cutting process, which revealed the crack expansion, development, evolution in the coal body and the corresponding lump coal formation mechanism, was performed in PFC2D. Moreover, a correlation was established between the cutting force and lump coal formation, and a statistical analysis method was proposed to determine the lump coal rate. The following conclusions are drawn from the results: (1) Based on a soft ball model, a coal wall cutting model is established. By setting the roller parameters based on linear bonding and simulating the roller cutting process of the coal body, the coal wall cutting process is effectively simulated, and accurate lump coal rate statistics are provided. (2) Under the cutting stress, the coal body in the working face underwent three stages-microfracture generation, fracture expansion, and fracture penetration - to form lump coal, in which the fracture direction is orthogonal to the cutting pressure chain. Within a certain range from the roller, as the cutting depth of the roller increased, the number of new fractures in the coal body first increases and then stabilizes. (3) Under the cutting stress, the fractured coal body is locally compressed, thereby forming a compact core. The formation and destruction of the compact core causes fluctuations in the cutting force. The fluctuation amplitude is positively related to the coal mass. (4) Because the simulation does not consider secondary damage in the coal, the simulated lump coal rate is larger than the actual lump coal rate in the working face; this deviation is mainly concentrated in large lump coal with a diameter greater than $300 \mathrm{~mm}$.
\end{abstract}

Keywords Fully mechanized face $\cdot$ Lump coal rate $\cdot$ Fracture evolution $\cdot$ Cutting force $\cdot$ Particle flow simulation

\section{Introduction}

As an important fossil fuel in China, coal is used as a raw material in various industries, including the chemical industry, and as an important source of industrial heat and kinetic energy. The lump coal rate, which is the proportion

Shengzhi Wang

15150027809@163.com

1 Key Laboratory of Deep Coal Resource Mining (CUMT), Ministry of Education, China University of Mining and Technology, Xuzhou 221116, Jiangsu, China

2 State Key Laboratory of Coal Resources and Safe Mining and School of Mines, China University of Mining and Technology, Xuzhou 221116, Jiangsu, China of lump coal with a diameter greater than $30 \mathrm{~mm}$ in the total coal volume, is an important indicator of the quality and value of coal products. The higher the lump coal rate is, the better the coal quality, the higher the coal price, and the lower the amount of dust at the coal mining face. Affected by factors such as coal seam conditions and coal mining technology, the coal lump rate in Chinese mines is only $15 \%$, which seriously restricts production efficiency improvements in coal enterprises (Deng et al. 2017). Taking the Shenfu mining area as an example, the output of underground lump coal through coal cutting and washing leads to a loss of 20\%-30\% (Fei 2017). Hence, increasing the lump coal rate in a fully mechanized face is the basis for increasing the lump coal rate in a mine. 
With this goal in mind, current research has mainly focused on the structural modification of coal winning machines and the optimization of coal mining processes. To increase the lump coal rate, Liu et al. (2009), Ge et al. (2018) and Cheng et al. (2008) analyzed the cutting speed of the shearer and parameters of roller cutting, whereas Qin et al. (2015) performed multiobjective optimization of the working face. Two methods are usually used to calculate the lump coal rate of the working face in coal mines: (1) selecting the amount of coal transported on a section of the scraper conveyor for manual statistical analysis and (2) simulating the cutting process of the work face through experiments to determine the lump coal rate. The first method is complicated to operate, which affects production and makes it impossible to accurately calculate the lump coal rate in the cutting process. The second method requires more manpower, material resources and financial resources, and because the statistical results must be compared and verified with the field, they cannot quickly reflect the change in the lump coal rate on the working surface. Hence, accurately calculating the block distribution law of a coal body after the roller has been cut is a problem that must be solved.

The discrete element method (DEM) is widely used in mining engineering (Liu et al. 2019a; Wang et al. 2014a, 2020; Bayisa et al. 2018; Shi et al. 2020), tunnel engineering (Chao et al. 2019; Boon et al. 2015), slope engineering and fracture mechanics (Ye et al. 2018; Zhao et al. 2012a; Janiszewski et al. 2019). PFC2D, a DEM simulation software package, has great advantages for studying relatively fragmented macroscopic objects, such as soil and stone piles (Gürsoy et al. 2017; Tian et al. 2018; Mehranpour and Kulatilake 2017; Yang et al. 2018). Liu et al. (2008) used PFC2D to conduct a simulated study on rock fragmentation and fracture development under the stress of rockfill from a microscopic perspective, and it showed that the selected microscopic parameters could reflect the macroscopic characteristics of the model to a certain extent. Similarly, PFC2D can also be used to study the failure process of intact coal masses. By analyzing granite components, Hu et al. (2019) established graniteflow models of different components and studied the development of fractures under pressure. Wang et al. (2014b) obtained the mesomechanical parameters of coal and rock masses using PFC2D and performed coal-rock tests under different confining pressures to analyze the changes in acoustic emission and fracture mesocharacteristics during fracture development.

In summary, PFC2D can be used to simulate the process of lump coal formation in a fully mechanized mining face. To address the abovementioned difficulty of determining the lump coal rate in a fully mechanized face at a mesoscopic level, this paper uses macro/meso theory as the basis for the use of mesoparameters in PFC2D. The macrocharacteristics of coal mining and lump coal formation are simulated, and the lump coal rate of the working face is determined.

\section{Establishment of a numerical simulation model}

\subsection{Engineering background}

The 42110 working face in the Liangshuijing Mine, which is a fully mechanized coal mining face, has a strike length of $4380 \mathrm{~m}$ and an inclined length of $240 \mathrm{~m}$. The Platts coefficient $f$ of the coal seam is in the range of 3-5, indicating that this seam is hard coal. To cut the coal, the working face adopts a roller shearer with a mining height of $3.0 \mathrm{~m}$ and a cutting depth of $0.865 \mathrm{~m}$. Because the price of lump coal is twice the price of powdered coal, it is very beneficial to develop a technology that can enhance the lump coal rate and increase the profit of the mine. Understanding the mechanism of lump coal production and the change law of the lump coal rate is the basis of studying this technology.

\subsection{Particle contact mechanics model}

The particle model is a complex model composed of a large number of discrete spherical particles or irregular particles (Wu et al. 2018). The movement of individual particles in the model follows Newton's laws of motion, and particle flow occurs when the whole model is subjected to external forces. The solution process of the particle flow contact model is highly complicated; however, this model can be simplified into a soft ball model and a hard ball model without generating large errors (Sun and Wang 2009). The soft ball model (Fig. 1) replaces the normal contact force between particles with a spring and a damper and the tangential contact force with a spring, a damper and a slider. The soft ball model does not consider the deformation of particles but replaces the particle deformation with the overlap between particles, which conforms to the state presented between particles when force is applied to the macroscopic model in PFC2D. The soft ball model is suitable for a stable model composed of multiple particles, and it is an important approach for connecting macroscopic properties with mesoparameters. For the soft ball model (Fig. 1), Cundall and Strack (1980) proposed the idea of discrete simulation of particulate matter. After more than 30 years of continuous improvement, this model has become an effective tool for obtaining mechanical parameters between particles. 

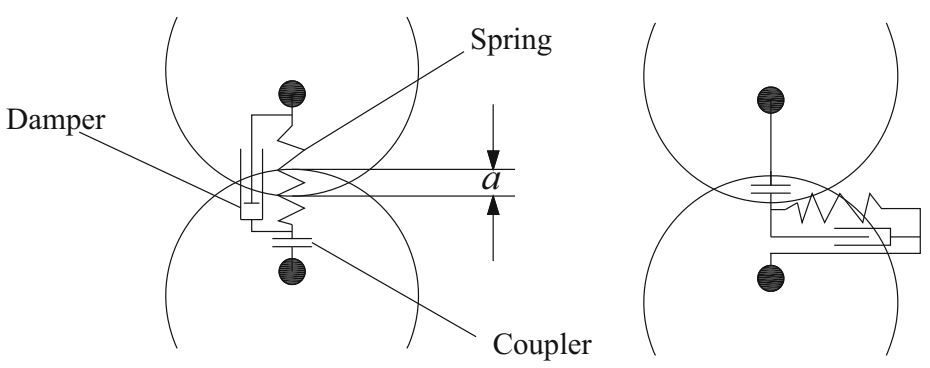

(a) Normal force

(b) Tangential force

Fig. 1 Soft ball model

\subsection{Building the initial simulation model}

In PFC2D, the coal body is simulated with a ball combination, whereas the roller is simulated with a wall command. Thus, an initial model with a length of $7500 \mathrm{~mm}$ and a height of $3000 \mathrm{~mm}$ is established. Considering the relationship between model size and operation speed, the diameter of the ball is set to $20-30 \mathrm{~mm}$, which is equivalent to a coal block with a ball size below $30 \mathrm{~mm}$. This approach can ensure both the operation speed and the simulation effect.
As a result of the low support pressure of the working face in a cut-off range during the mining process (Fig. 2), the crushing effect of the support pressure on the coal body is not considered at this time. To reach the initial equilibrium quickly, the initial contact model is set to linear contact. The initial parameters of the model are shown in Table 1.

\subsection{Model parameter setting method}

The parameters that can be set directly in the PFC2D model are mesoparameters, and the model simulates a

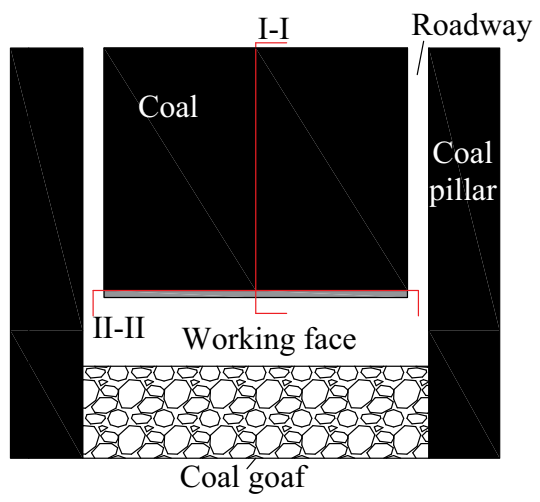

(a) Top view of the working face

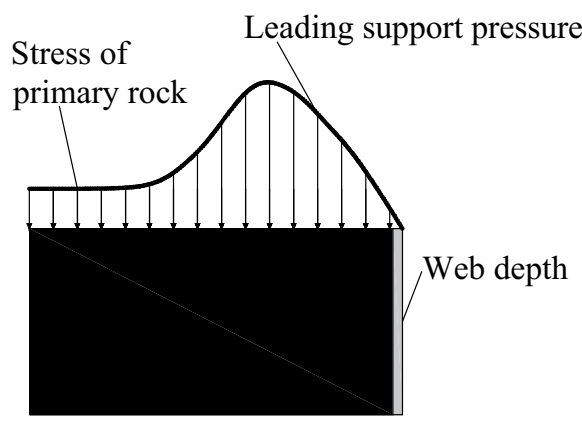

(b) I- I profile

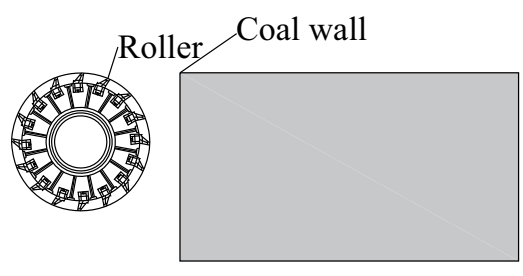

(c) II- II profile

Fig. $23 \mathrm{D}$ view of the working face 
Table 1 Initial model parameters

\begin{tabular}{llll}
\hline $\begin{array}{l}\text { Elastic modulus of the } \\
\text { linear bond (GPa) }\end{array}$ & $\begin{array}{l}\text { Gravitational } \\
\text { acceleration }(\mathrm{m} / \\
\left.\mathrm{s}^{2}\right)\end{array}$ & $\begin{array}{l}\text { Ball } \\
\text { density } \\
\left(\mathrm{kg} / \mathrm{m}^{3}\right)\end{array}$ & $\begin{array}{l}\text { Average } \\
\text { ratio }\end{array}$ \\
\hline 1 & 9.81 & 1400 & $1 \times 10^{-4}$ \\
\hline
\end{tabular}

macroscopic model composed of macromaterials; thus, there is a certain conversion relationship between the mesoparameters and the macroparameters. The bond model used for the PFC2D simulation of rock materials is the linear parallel bond model. Zhao et al. (2012b) summarized the research performed by domestic and foreign scholars on the influence of the macroscopic characteristics of the parallel bonding mesoparameters on particle flow. Moreover, Zhao et al. (2012b) established a simulation of the mechanical behavior of rocks and obtained the relationship between the macroparameters and the mesoparameters, as shown in Eq. (1).

$$
\left\{\begin{array}{l}
v=\phi_{v}\left(\frac{k_{\mathrm{s}}}{k_{\mathrm{n}}}, \frac{L}{R}, \frac{R_{\max }}{R_{\min }}\right) \\
E=E_{\mathrm{c}} \phi_{E}\left(\frac{k_{\mathrm{s}}}{k_{\mathrm{n}}}, \frac{L}{R}, \frac{R_{\max }}{R_{\min }}\right) \\
\sigma_{\mathrm{c}}=\bar{\sigma}_{\mathrm{c}} \phi_{\mathrm{c}}\left(\frac{E_{\mathrm{c}}}{\bar{\sigma}_{\mathrm{c}}}, \frac{\bar{c}}{\bar{\sigma}_{\mathrm{c}}}, \mu, \frac{k_{\mathrm{s}}}{k_{\mathrm{n}}}, \frac{L}{R}, \frac{R_{\max }}{R_{\min }}\right)
\end{array}\right.
$$

The macroparameters in Eq. (1) are defined as follows: $v$ is Poisson's ratio, $E$ is the elastic modulus, and $\sigma_{\mathrm{c}}$ is the compressive strength.

The mesoparameters in Eq. (1) are defined as follows: $E_{\mathrm{c}}$ is the particle contact modulus; $k_{\mathrm{s}} / k_{\mathrm{n}}$ is the normal-toshear stiffness ratio; $\mu$ is the particle friction coefficient; $\phi_{v}, \phi_{E}$, and $\phi_{\mathrm{c}}$ are functions of Poisson's ratio, elastic modulus, and compressive strength, respectively; $\bar{\sigma}_{\mathrm{c}}$ and $\bar{c}$ are tensile strength and cohesion, respectively; $L$ is the model height; and $R_{\max } / R_{\min }$ is the ratio of the maximum and minimum radius in the model.

Through a combination of Eq. (1) and his own research results, Cong et al. (2015) increased the accuracy of the parameters of the macroscopic model, and he added parameters unique to the linear parallel bond. In this approach, the expressions of $v$ and $E$ in Eq. (1) are modified as follows:

$$
\left\{\begin{array}{c}
v=\phi_{v}\left(\frac{k_{\mathrm{s}}}{k_{\mathrm{n}}}, \frac{\overline{k_{\mathrm{s}}}}{\overline{k_{\mathrm{n}}}}, \bar{\lambda}, \overline{E_{\mathrm{c}}}, E_{\mathrm{c}}\right) \\
E=\phi_{E}\left(\frac{k_{\mathrm{s}}}{k_{\mathrm{n}}}, \frac{\overline{k_{\mathrm{s}}}}{\overline{k_{\mathrm{n}}}}, \bar{\lambda}, \bar{E}_{\mathrm{c}}, E_{\mathrm{c}}\right)
\end{array}\right.
$$

where $\overline{k_{\mathrm{s}}} / \overline{k_{\mathrm{n}}}$ is the bond normal-to-shear stiffness ratio, $\bar{\lambda}$ is the linear parallel bond radius multiplier, and $\bar{E}_{\mathrm{c}}$ is the linear parallel bond modulus.
The linear parallel bond model defines the mechanical behavior of the interface between two particles from a microscopic view: an infinitesimal, linear elastic (nontensioned), frictional interface with a finite size that carries a force and moment. The linear force and bonding interface are shown in Fig. 3. The first bonding method is a linear model (Fig. 4a) that does not resist relative rotation and limits the tangential slip of the particles by applying a Coulomb limit to the shear force. The second bonding method is the parallel bonding model (Fig. 4b). When the parallel bonding model is bonded, the relative rotation of the particles is inhibited, and the corresponding behavior is linear elastic until the adhesive is broken by exceeding the strength limit. When the linear parallel bond model breaks due to stress, it no longer carries any load. The bondless linear parallel bond model is equivalent to the linear model.

The following expression defines a relationship between some of the variables in Fig. 4:

$\bar{g}_{\mathrm{s}}=\sum \Delta \delta_{\mathrm{n}}$

where, $\Delta \delta_{\mathrm{n}}$ is the relative normal displacement increment between balls, and $\overline{g_{\mathrm{s}}}$ is the sum of displacement.

\subsection{Test piece physics and simulation test}

In PFC2D, after the proportional relationship between the meso- and macroparameters is known, an additional calibration procedure is required; hence, given the macromechanical properties of a group of coal specimens, the mesoscopic parameters are determined (He 2015). A uniaxial compression test (Fig. 5a) and a Brazilian splitting test (Fig. 5b) were used to determine the relevant physical and mechanical parameters of the coal body.

The macroparameters of the sample determined by the test are shown in Table 2.

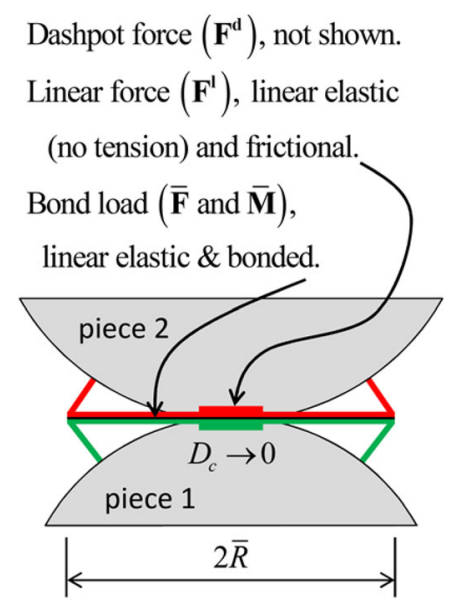

Fig. 3 Linear parallel bond model between two balls 


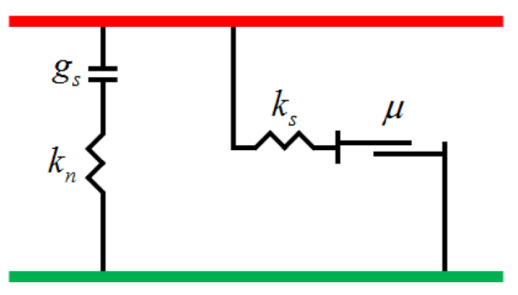

(a) Linear model

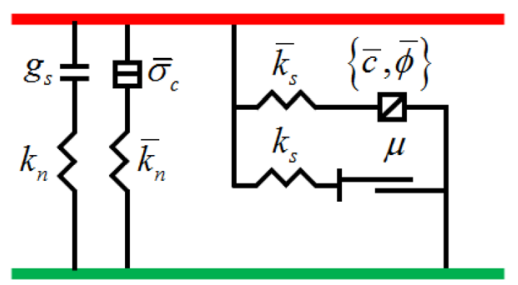

(b) Linear parallel bond model

Fig. 4 Linear model and linear parallel bond model

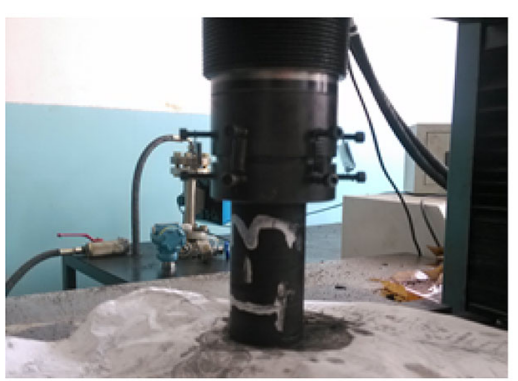

(a) Uniaxial compression test

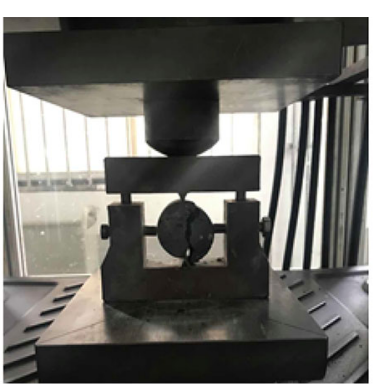

(b) Brazilian splitting test

Fig. 5 Test images

Table 2 Macroscopic parameters of coal

\begin{tabular}{llll}
\hline $\begin{array}{l}\text { Elastic } \\
\text { modulus } \\
(\mathrm{GPa})\end{array}$ & $\begin{array}{l}\text { Poisson's } \\
\text { ratio }\end{array}$ & $\begin{array}{l}\text { Uniaxial compressive } \\
\text { strength }(\mathrm{MPa})\end{array}$ & $\begin{array}{l}\text { Tensile } \\
\text { strength } \\
(\mathrm{MPa})\end{array}$ \\
\hline 3.47 & 0.16 & 37 & 2.4 \\
\hline
\end{tabular}

The macroparameters were obtained based on the test, and the uniaxial compression test and Brazilian splitting test were designed by using PFC2D. The uniaxial compression model with design dimensions of $100 \mathrm{~mm} \times 50$ $\mathrm{mm}$ and the Brazilian splitting model with a diameter of $50 \mathrm{~mm}$ and a loading plate of $60 \mathrm{~mm}$ are shown in Fig. 7. In the Brazilian splitting test, the thickness of the test piece is involved. In the PFC2D model, the thickness of the test piece can be set to 1 , and the tensile strength of the test piece can be calculated with Eq. (4):

$\sigma_{\mathrm{t}}=\frac{2 P}{\pi d t}$

where $P$ is the maximum load $(\mathrm{N})$ when the failure of the test piece occurs, $d$ is the diameter $(\mathrm{m})$ of the test piece, and $t$ is the thickness (m) of the disc of the test piece.

$P=\sigma_{\mathrm{f}} \cdot S$

where $\sigma_{\mathrm{f}}$ is the maximum stress in the event of failure (MPa), and $S$ is the ballast plate area $\left(\mathrm{m}^{2}\right)$.
The loading method for uniaxial compression is controlled by displacement. The specific parameters are as follows: the crosshead displacement is $0.02 \mathrm{~mm} / \mathrm{step}$, and the direction is vertical downward. The specimen failure mode and crack development in the uniaxial compression and Brazilian splitting simulation tests are shown in Figs. $6 \mathrm{~b}$ and $7 \mathrm{~b}$, respectively. The test values were averaged to obtain the red curve in Fig. 8.

The macroparameters of coal obtained through the model tests are listed in Table 3. The results show that the parameters obtained through the model test are basically

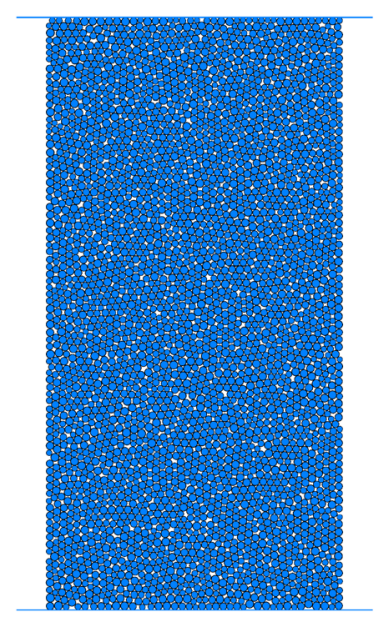

(a) Numerical model

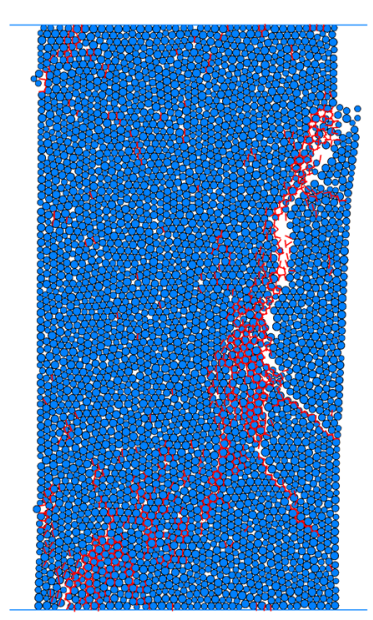

(b) Specimen damage
Fig. 6 Uniaxial compression simulation test 


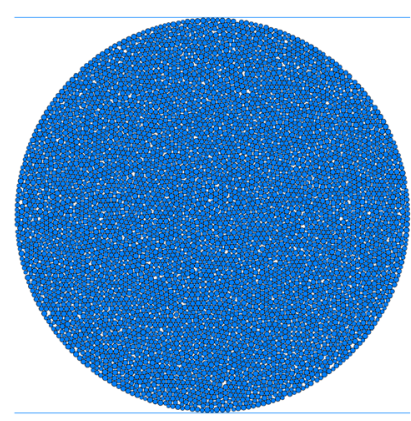

(a) Numerical model

Fig. 7 Brazilian splitting simulation test

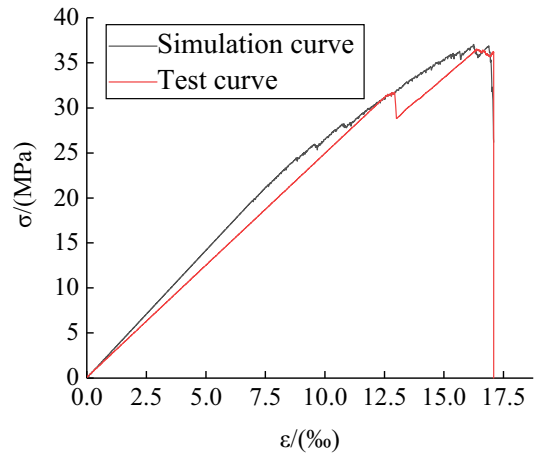

(a) Uniaxial compression test

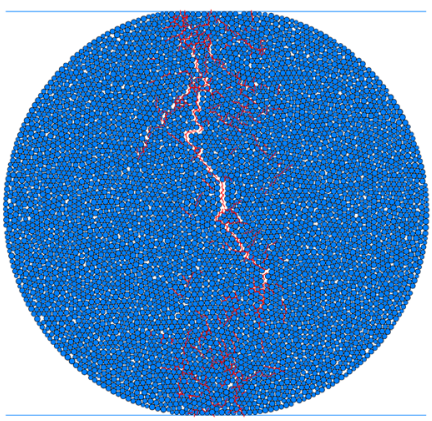

(b) Specimen damage

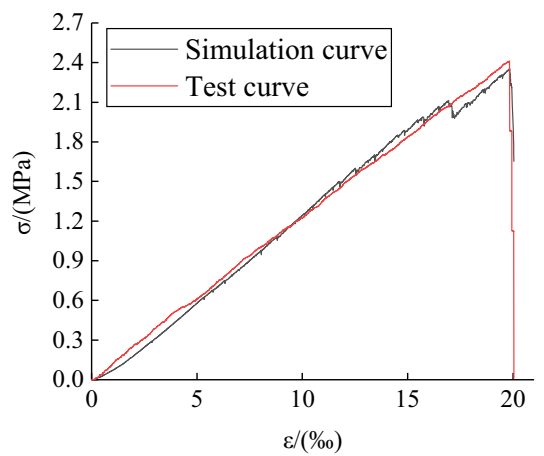

(b) Brazilian splitting test

Fig. 8 Stress-strain curve

Table 3 Macroparameter check of the initial model

\begin{tabular}{lllll}
\hline Item & Elastic modulus $(\mathrm{GPa})$ & Poisson's ratio & Uniaxial compressive strength (MPa) & Tensile strength $(\mathrm{MPa})$ \\
\hline Simulation parameters & 3.50 & 0.16 & 37.4 & 2.38 \\
Test parameters & 3.47 & 0.16 & 37.0 & 2.40 \\
\hline
\end{tabular}

Table 4 Mesoparameters of the initial simulation model

\begin{tabular}{llll}
\hline Mesoparameter & Value & Mesoparameter & Value \\
\hline Linear parallel bond modulus $\left(\overline{E_{\mathrm{c}}}\right)$ & $1.6 \mathrm{GPa}$ & Particle contact modulus $\left(E_{\mathrm{c}}\right)$ & $1.6 \mathrm{GPa}$ \\
Normal stiffness $\left(k_{\mathrm{n}}\right)$ & $0.6 \mathrm{GPa}$ & Bond normal-to-shear stiffness ratio $\left(\overline{k_{\mathrm{s}}} / \overline{k_{\mathrm{n}}}\right)$ & 2.5 \\
Normal-to-shear stiffness ratio $\left(k_{\mathrm{s}} / k_{\mathrm{n}}\right)$ & 2.5 & Tensile strength $\left(\overline{\sigma_{\mathrm{c}}}\right)$ & $22 \mathrm{MPa}$ \\
Friction angle $(\bar{\phi})$ & 30 & Cohesion $(\bar{c})$ & $6.3 \mathrm{MPa}$ \\
\hline
\end{tabular}

the same as the given parameters. Therefore, it can be determined that the mesoparameters corresponding to the stress-strain curve in Fig. 8, which are consistent with coal, are the mesoparameters sought in this paper.
Based on the research of Liu et al. (2019b) and Dai et al. (2016) on the compressive strength and tensile strength of a particle flow model, Eqs. (1) and (2) are combined, model check tests are performed, and the mesoparameters of coal are obtained as shown in Table 4. 


\subsection{Roller simulation and movement process command assignment}

The roller is the main part of the shearer in the process of coal cutting. Therefore, in the study of shearer cutting conditions, the roller is actually the main research object. The facet is the basic element of the wall, and in PFC2D, the facet element is a rigid body that will not be deformed by external forces. In the actual coal mining process, the stiffness and strength of the roller are much greater than the strength and stiffness of the coal body. Therefore, it is feasible to simulate a roller with a wall composed of facet elements. However, to achieve the cutting effect, it is necessary to apply a bonding parameter between the walls and the balls. Because there is no adhesion between the roller and the coal walls in reality, a linear bond model is set between the walls and balls. Considering that the roller and the coal wall are in dynamic contact, when the model is assigned parameters, the contact force between the wall and the particles can be set to a large value to reduce the number of particles passing through the wall during the model calculation. The assignments are shown in Table 5.

The ideal roller model for simulation directly uses the circle command to generate a circular wall and then assigns a horizontal displacement in the $X$ direction to simulate the roller cutting the coal. However, in the actual situation, the rotary table of the roller does not directly participate in coal cutting but rather participates only in the transmitting force and the bearing capacity. The blade that is installed on the rotary table of the roller is actually responsible for cutting. Therefore, to simulate a realistic numerical model, picks must be added to the roller model. The generated roller model is shown in Fig. 9c. The use of this roller model is simplified from the actual 3D roller model (Fig. 9a). Considering the reliability of the simulation and the speed of calculation, a section of the 3D roller model is taken (Fig. 9b), and the pick length is shortened. The distance between two adjacent cutting tips is $300 \mathrm{~mm}$.

The actual coal shearer cuts the coal wall while simultaneously rotating the roller and moving it laterally. To ensure authenticity, the roller rotates horizontally while maintaining its rotation. In the simulation cutting process, the fixed simulation time step is $5 \times 10^{-5} \mathrm{~s}$, and the lateral displacement speed of the roller is set to $0.5 \mathrm{~m} / \mathrm{s}$ so that for every 1000 steps, the roller will move $25 \mathrm{~mm}$ horizontally to the right. Moreover, the roller rotates clockwise around its center. To match the roller rotation speed with the horizontal displacement speed, the roller rotation speed is set to $1.25 \mathrm{rad} / \mathrm{step}$. With the combination of these two parameters, the roller can keep moving horizontally and straight to the right. This process is the same as the actual situation and meets the simulation expectations.

\subsection{Lump coal rate statistical method}

After the simulation is completed, the lump coal rate must be calculated. The statistical method is shown in Fig. 10. In the initial model, the type of contact force between the balls is a linear parallel bond. When the balls are cut by the roller model to break the force chain, the type of contact force between the particles becomes a linear bond. Based on the different properties of the interparticle force chain

Table 5 Wall-ball contact bond parameter

\begin{tabular}{llllll}
\hline Parameter & Bond gap $(\mathrm{mm})$ & Linear modulus $(\mathrm{GPa})$ & Normal-to-shear stiffness ratio & Normal stiffness $(\mathrm{GPa})$ & Shear stiffness $(\mathrm{GPa})$ \\
\hline Value & $5 \times 10^{-5}$ & 500 & 0.5 & 3 & 1 \\
\hline
\end{tabular}

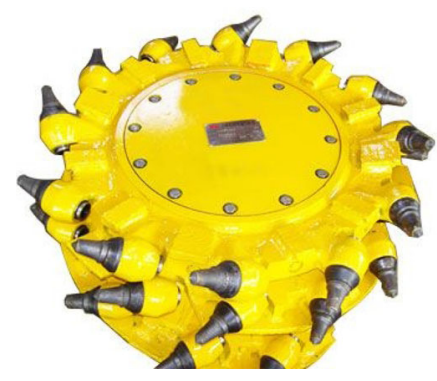

(a) Actual roller
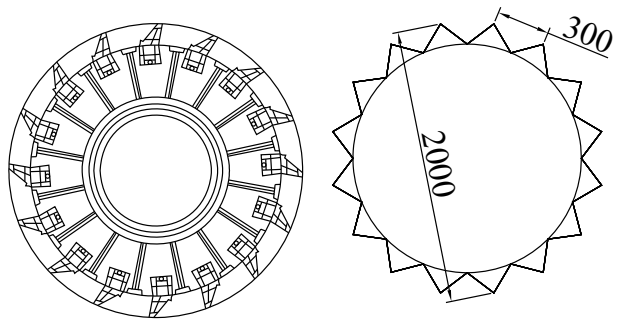

(b) Roller profile

(c) Roller simplified model

Fig. 9 Schematics of roller 
before and after failure, the built-in FISH language of PFC2D is used to distinguish the type of contact force between the balls cut by the roller model to determine whether the particles are lumped, calculate the lump size, and compute the corresponding statistics.

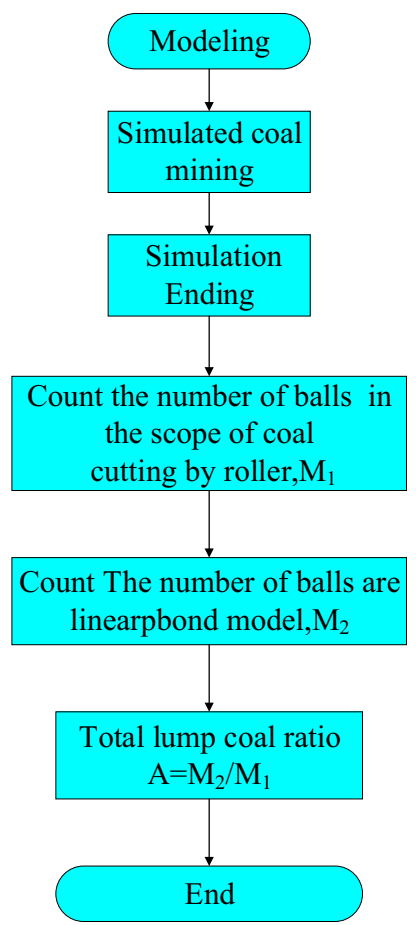

Fig. 10 Flow chart of lump coal rate statistics

\section{Development and evolution of fractures during coal cutting}

\subsection{Fracture development}

PFC2D particle flow software can directly monitor crack development during excavation through Fracture, a built-in FISH command. The crack development process is shown in Fig. 11. Figure 11 shows that the formation of lump coal can be divided into three stages. (1) Fractures are generated when the roller contacts the coal wall (Fig. 11a). Due to the short contact time, the cutting force of the roller does not sufficiently damage the coal wall. The coal block still cannot be separated from the coal body due to the cohesive force. As the roller moves to the right, an increasing number of fractures are generated due to cutting. (2) The fractures expand further. Before the lump coal peels off from the coal wall (Fig. 11b), the coal wall has already produced larger fractures and a small amount of pulverized coal after being cut. (3) Lump coal is generated, and as cutting progresses (Fig. 11c), the fractures develop, and large coal lumps are produced at the boundaries of several major fissures and coal bodies.

Figure 12 shows that when the roller just touches the coal wall, a few fractures are generated. Until the simulation operation reaches 85,000 steps, the number of fractures increases steadily with a relationship of 500 fractures per 5000 steps. The reason for this phenomenon is explained here. (1) The roller just contacts the coal wall, and the increase in the free surface is accompanied by an increase in the number of fractures. This increase in the free surface affects the fractures and promotes the

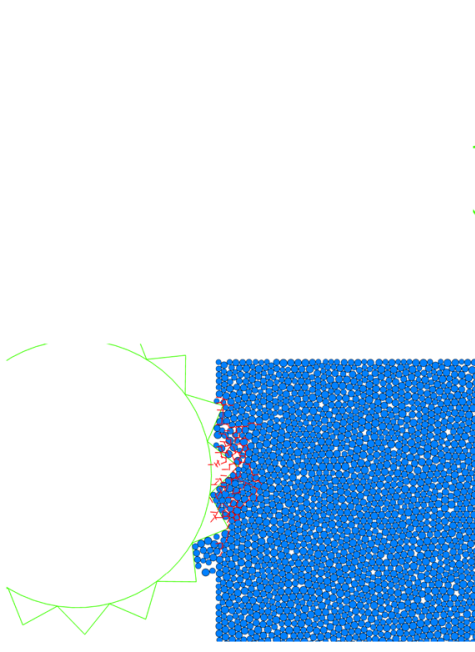

(a)

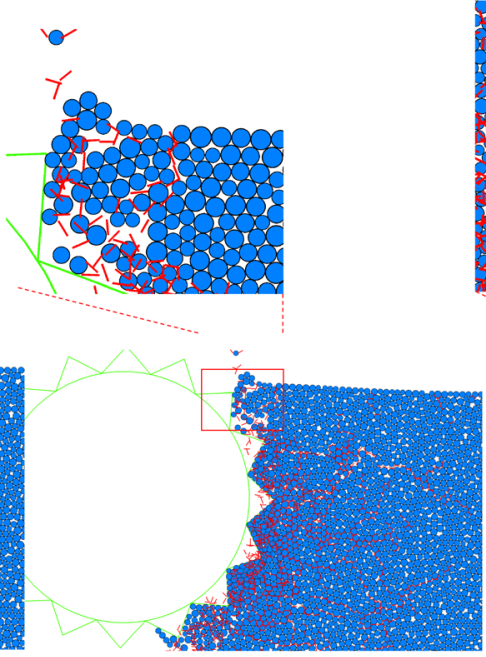

(b)

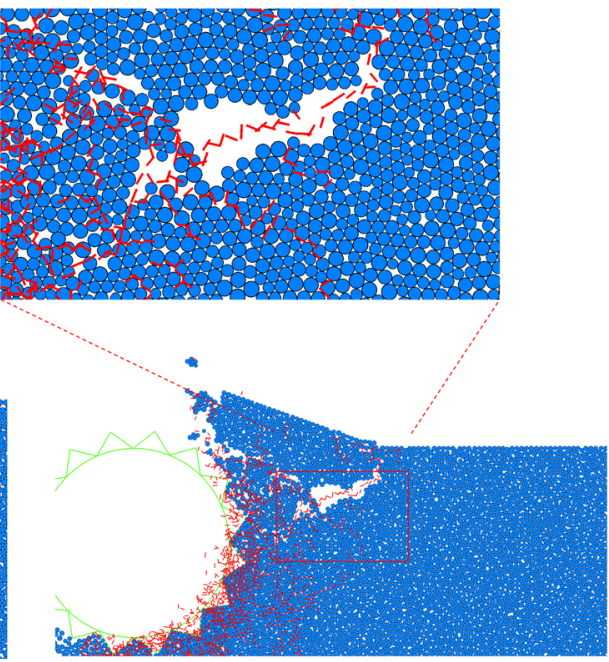

(c)

Fig. 11 Fissure development 


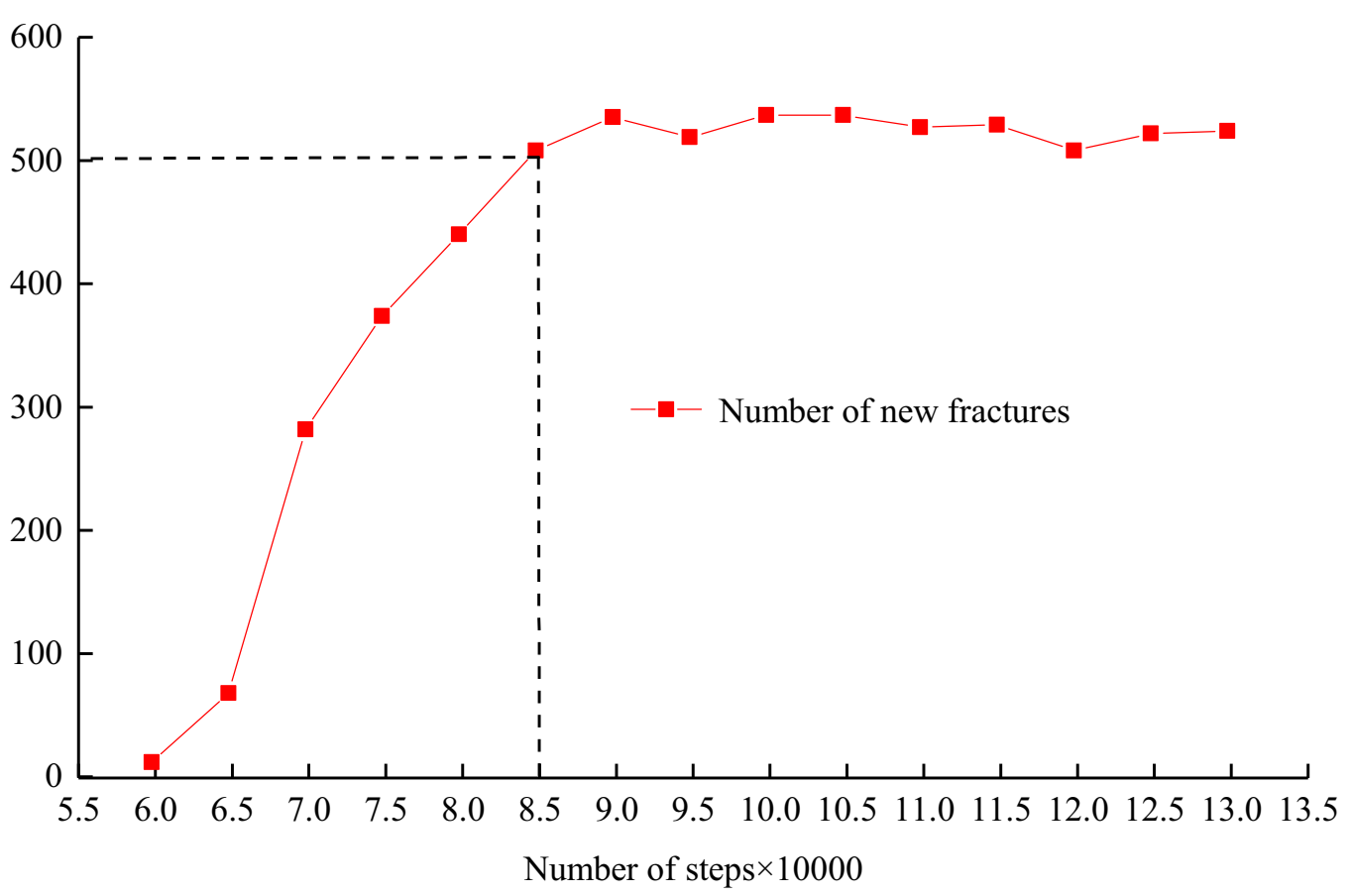

Fig. 12 Development of fractures

development of the fractures. Thus, before 85,000 steps, the model undergoes free surface development. (2) The development of fractures to a certain degree causes lump coal to fall off, which will reduce the number of free surfaces of the coal body. The more fractures develop, the faster the lump coal falls off, and the larger the reduction in the free surface. Therefore, there is an equilibrium point where the numbers of free surface generations and losses are approximately the same. At this equilibrium point, the maximum number of fractures develops. This point is reflected in Fig. 12 after 85,000 steps.

An area with a certain distance from the roller is selected to investigate the development of mesofractures (Fig. 13). In areas where there are more fractures, the force chain between the balls is broken, and larger fractures are generated. However, the balls still maintain a relatively stable alignment, and fewer fractures are generated farther from the roller.

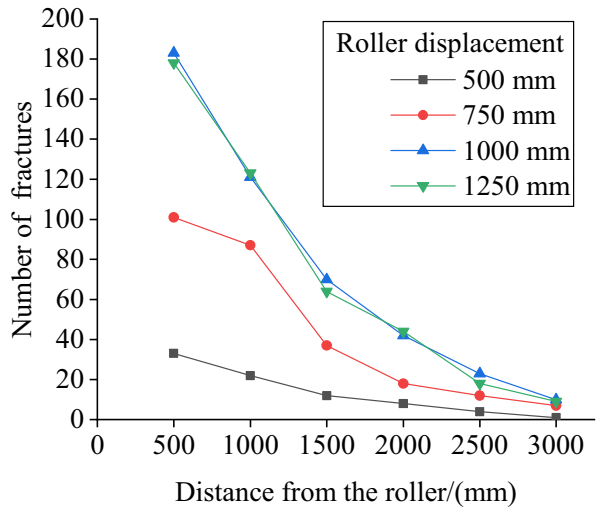

Fig. 14 Number of fractures as a function of the horizontal distance from the roller

As shown in Fig. 14, a farther distance from the roller results in fewer fractures and a smaller downward trend. The range of influence of the roller in the model is within a

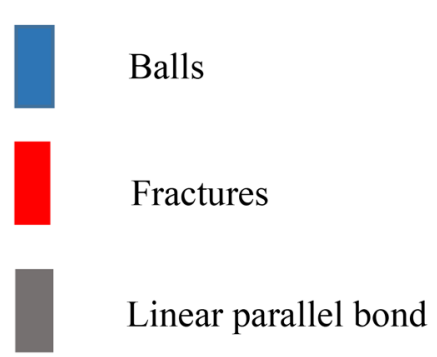

Fig. 13 Microfractures

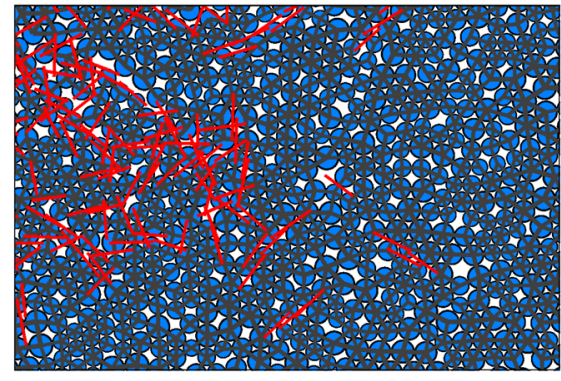




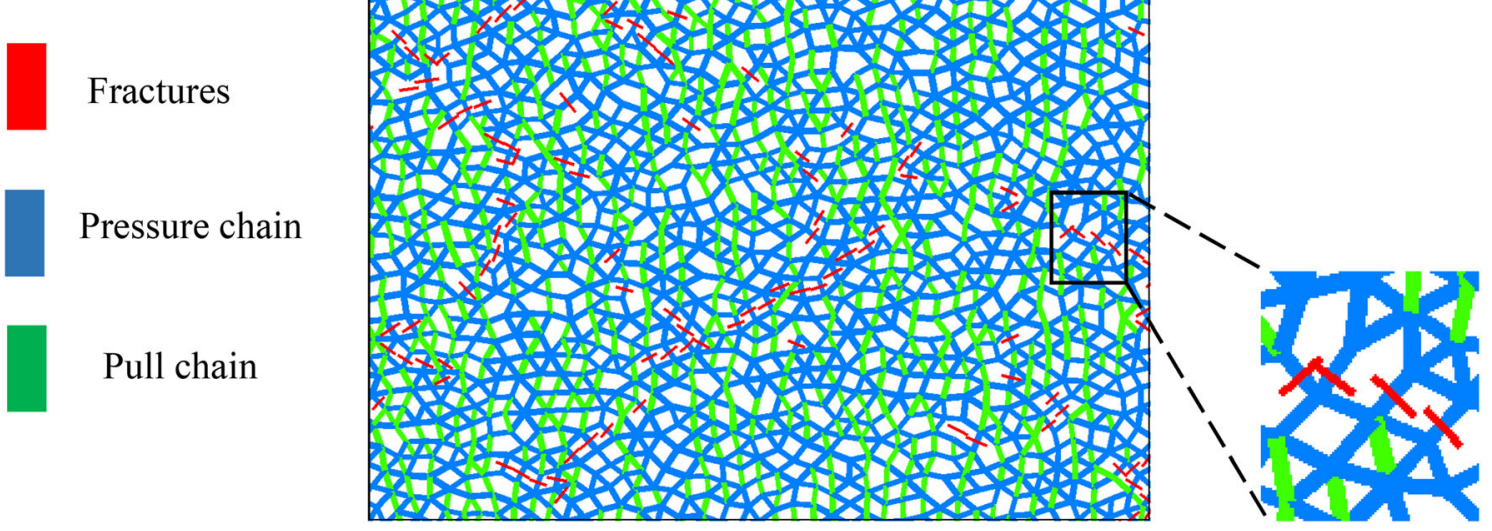

Fig. 15 Microfractures and force chains

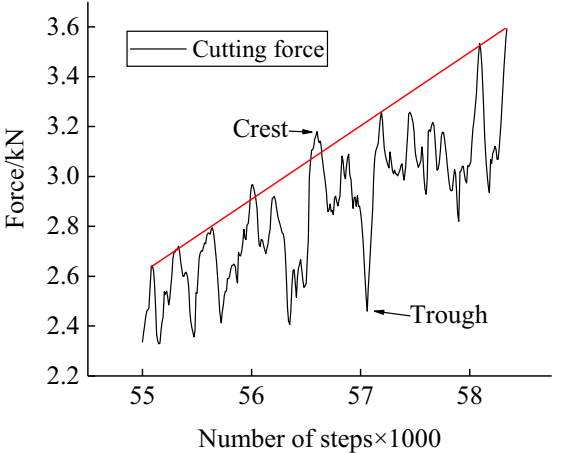

Fig. 16 Initial cutting force

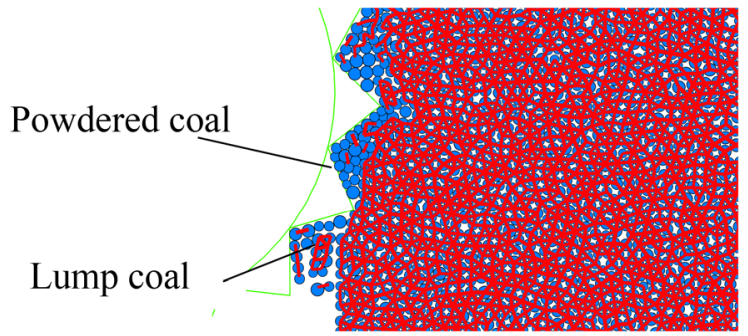

Fig. 17 Coal block coal powder discharge

horizontal distance of $3000 \mathrm{~mm}$. The number of fractures tends to stabilize when the picks enter the model beyond $1000 \mathrm{~mm}$, indicating that the development of coal fractures is maximized.

Microscopic analysis reveals that fractures are generated in the middle of the pressure chain, and they intersect approximately perpendicularly with the connection line of the pressure chain. Liu (2009b) performed uniaxial compression experiments with coal samples and found that the compressive strength, shear strength, and tensile strength of coal decrease sequentially. Most coal samples destroyed by uniaxial compression are actually sheared, not simply crushed. In Fig. 15, the fractures are orthogonal to the

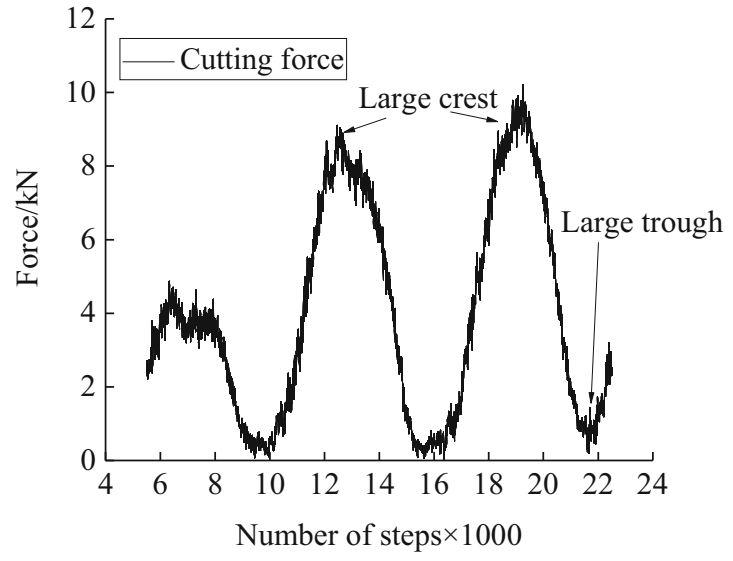

Fig. 18 Cutting force

pressure chain, and no cracks are generated between the tension chains.

\section{Correlation analysis between the cutting force and lump coal rate}

As shown in Fig. 16, When the roller rotates, the contact force between the roller and the coal wall gradually increases. When the contact force reaches the compressive strength of the coal body, the coal body starts to rupture, forming a compact core. During this process, the cutting force increases. From Fig. 17, as the roller continues to rotate, the compact core is destroyed, and the accumulated energy in the compact core is released at a very fast rate. With the release of energy, small pieces of coal and coal powder are discharged along the roller surface at a very high speed. During this process, the cutting force reaches the highest point in the stage, which is also the critical point of compact core damage. Afterward, the compact core damage and the cutting force decline. Because the roller rotates at a high speed, a new compact core is formed 


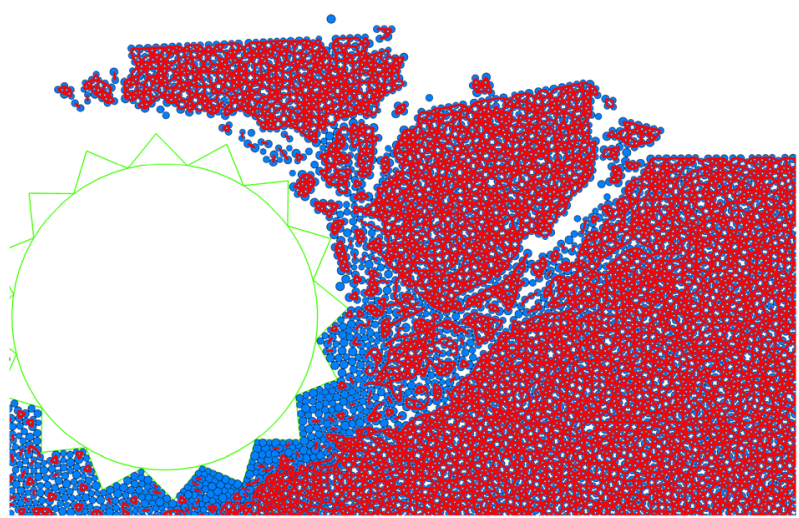

Fig. 19 Large lump coal stripping

soon after the previous compact core is destroyed. The coal picking process is a process of cutting in, forming a compact core, and destroying the compact core, which is also the reason for the fluctuation in the cutting force of the pick. With the deepening of the cutters of the roller, the crest value and the trough value of the cutting force gradually increase, which is caused by the gradually increasing force of the roller on the entire coal wall.

As shown in Fig. 18, the value of the crest increases to a certain extent, and then a decline occurs due to the development of distant fractures, causing the large coal to fall off in advance. The diameter of large coal is more than the distance between two picks of roller that is $300 \mathrm{~mm}$, as shown in Fig. 9c. Large pieces of coal fall off the coal wall, which will result in a certain distance between the roller and the coal wall. Figure 19 reveals that the roller and the coal wall are composed of powdered coal and small pieces of lump coal. This process is mainly the interaction between the roller and the large block of coal, and the cutting force will not increase again until the roller contacts the coal wall again.

The lump coal distribution after the model calculation is completed is shown in Fig. 20. As the roller moves to the right, the individual balls gradually fall due to the acceleration of gravity and the cutting force of the roller, and most of them are deposited under the roller. Due to the action of the roller and the boundary, more lump coal is
Table 6 Lump coal statistics

\begin{tabular}{|c|c|c|c|}
\hline \multirow{2}{*}{$\begin{array}{l}\text { Scale } \\
(\mathrm{mm})\end{array}$} & \multicolumn{2}{|l|}{ Lump coal rate $(\%)$} & \multirow[t]{2}{*}{ Deviatior } \\
\hline & $\begin{array}{l}\text { Working face of } \\
\text { Liangshuijing Mine }\end{array}$ & $\begin{array}{l}\text { Simulation } \\
\text { test }\end{array}$ & \\
\hline$>300$ & 13.9 & 19.7 & +5.8 \\
\hline $80-300$ & 17.4 & 16.7 & -0.7 \\
\hline $30-80$ & 20.4 & 21.3 & +0.9 \\
\hline Total & 51.7 & 57.7 & +6.0 \\
\hline
\end{tabular}

generated at the boundary. After the lump coal is completely separated from the coal wall, although it is also affected by gravitational acceleration and roller cutting, the hinge and linear contact with the coal wall fail to decrease in time, forming obvious separations of large lump coal and small lump coal.

After the simulation is completed, the lump coal rate is calculated according to the method provided in Fig. 10. Based on the postprocessing statistics, the lump coal rate of the model is $57.70 \%$, and the proportion of each lump size corresponds to the actual measurement of the working face of the Liangshuijing Mine, as shown in Table 6.

The comparison in Table 6 reveals that the proportion of scale between 30 and $80 \mathrm{~mm}$ in the actual working face of the Liangshuijing coal mine is not much different from the results of the simulation tests. The largest difference is for large lump coal, which has a deviation of $5.8 \%$. The main reason for this gap is that after the large lump coal is cut on the actual working surface, it falls to the scraper conveyor, resulting in secondary damage, and is then broken into powdered coal and smaller lump coal. The coal in the simulation falls on the coal pile, thereby reducing the secondary damage of large coal; this phenomenon is also the main reason for the error between the simulation and the actual working face.

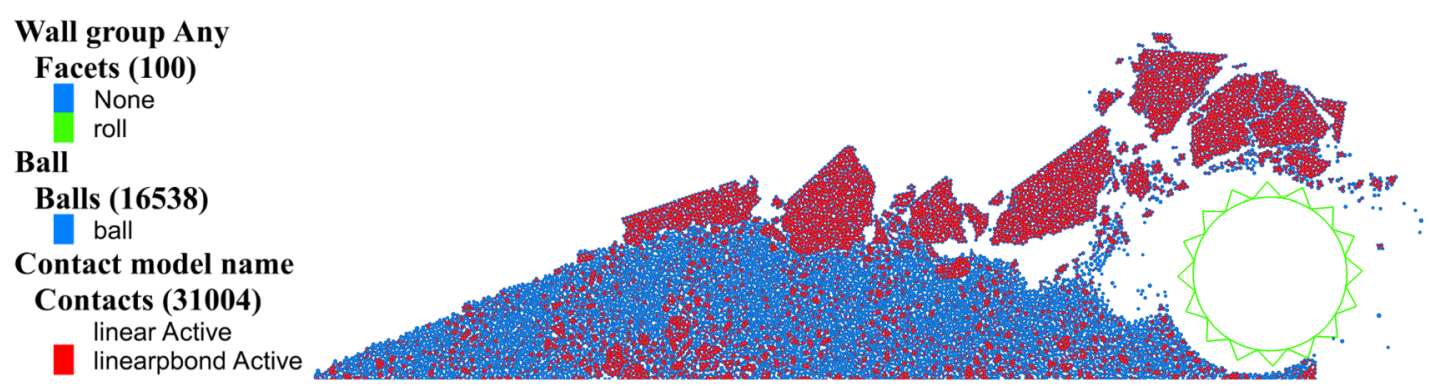

Fig. 20 End of simulation 


\section{Conclusion}

(1) A method for modeling a roller cutting a coal wall and for the subsequent statistical analysis of the lump coal rate is proposed. Based on a soft ball model, a coal wall cutting model is established. The relationship between the macroscopic mechanical parameters and the microscopic mechanical parameters of coal is determined not only through formula derivation and laboratory testing but also by setting the roller parameters based on linear bonding, simulating the process of cutting coal with the roller, and designing a statistical method for analyzing the lump coal rate after mining. These methods can effectively simulate the coal wall cutting process and provide accurate statistics of the lump coal rate in a fully mechanized mining face.

(2) The evolution rules of coal fractures under the action of the cutting force, which constitute the microfracture generation stage, the fracture expansion stage and the lump coal detachment from the coal wall, are obtained. The fractures are generated between the pressure chains and have an orthogonal relationship with the pressure chains. The number of new fractures gradually increases within a fixed time until the relationship of 500 cracks per 5000 steps gradually stabilizes. There are fewer fractures as the horizontal distance from the roller increases. Within $3000 \mathrm{~mm}$, after the cutting depth of the roller exceeds $1000 \mathrm{~mm}$, the fracture development in front of the roller tends to be stable.

(3) The mechanism of lump coal formation is revealed. The formation and destruction of compact cores cause the cutting force of the roller to fluctuate. A large change between the crest and trough of the cutting force wave is accompanied by the production of large lump coal with a diameter greater than $300 \mathrm{~mm}$. In contrast, a small change between the crest and trough of the cutting force wave is accompanied by the production of small lump coal with a diameter of $300 \mathrm{~mm}$.

(4) A statistical analysis method for lump coal rate is proposed and compared with field measurements. The results show that the main reason why the simulated statistical lump coal rate is larger than that of the actual working face is because, at the actual working face, the large lump coal is dropped on the scraper conveyor, causing secondary damage. This secondary damage is not considered in the model.

Open Access This article is licensed under a Creative Commons Attribution 4.0 International License, which permits use, sharing, adaptation, distribution and reproduction in any medium or format, as long as you give appropriate credit to the original author(s) and the source, provide a link to the Creative Commons licence, and indicate if changes were made. The images or other third party material in this article are included in the article's Creative Commons licence, unless indicated otherwise in a credit line to the material. If material is not included in the article's Creative Commons licence and your intended use is not permitted by statutory regulation or exceeds the permitted use, you will need to obtain permission directly from the copyright holder. To view a copy of this licence, visit http://creativecommons. org/licenses/by/4.0/.

Funding The funding was supported by National Natural Science Foundation of China (No. 51974294).

\section{References}

Bayisa R, Nengxiong X, Gang M (2018) An equivalent discontinuous modeling method of jointed rock masses for DEM simulation of mining-induced rock movements. Int $\mathrm{J}$ Rock Mech Min Sci 108:1-14. https://doi.org/10.1016/j.ijrmms.2018.04.053

Boon CW, Houlsby GT, Utili S (2015) Designing tunnel support in jointed rock masses via the DEM. Rock Mech Rock Eng 2:603-632. https://doi.org/10.1007/s00603-014-0579-8

Chao L, Liufeng P, Fei W et al (2019) Three-dimensional discrete element analysis on tunnel face instability in cobbles using ellipsoidal particles. Materials. https://doi.org/10.3390/ ma12203347

Cheng X, Du C, Li J (2008) Analysis of shearer drum and lump coal percentage. Coal Mine Mach 12:76-77. https://doi.org/10.3969/j. issn.1003-0794.2008.12.033

Cong Y, Wang Z, Zheng Y et al (2015) Experimental study on microscopic parameters of brittle materials based on particle flow theory. Chin J Rock Mech Eng 6:1031-1040. https://doi. org/10.11779/CJGE201506009

Cundall P, Strack O (1980) Discussion: a discrete numerical model for granular assemblies. Geotechnique 30:331-336. https://doi. org/10.1680/geot.1980.30.3.331

Dai F, Xu Y, Zhao T et al (2016) Loading-rate-dependent progressive fracturing of cracked chevron-notched Brazilian disc specimens in split Hopkinson pressure bar tests. Int J Rock Mech Min Sci 88:49-60. https://doi.org/10.1016/j.ijrmms.2016.07.003

Deng G, Qi X, Wang L (2017) Mechanism and application of lump coal rate improvement based on hydraulic fracturing. J Xi' an Univ Sci Technol 2:187-193. https://doi.org/10.13800/j.cnki. xakjdxxb.2017.0207

Fei P (2017) Study on the technology of increasing the rate of lump coal in large mining height fully mechanized of hydraulic fractured coal seam. Dissertation, Xi' an University of Science and Technology

Ge S, Qin D, Hu M et al (2018) Multi-objective optimization for cutting performance of the variable speed cutting shearer under different conditions. J China Coal Soc 8:2338-2347. https://doi. org/10.13225/j.cnki.jccs.2017.1542

Gürsoy S, Chen Y, Li B (2017) Measurement and modelling of soil displacement from sweeps with different cutting widths. Biosys Eng 161:1-13. https://doi.org/10.1016/j.biosystemseng.2017.06. 005

He X (2015) Failure mode transition for rock cutting: theoretical, numerical and experimental modelling. Dissertation, The University of Adelaide

Hu X, Ji K, Liu J et al (2019) Discrete element simulation study on the influence of microstructure heterogeneity on creep characteristics of granite. Chin J Rock Mech Eng 10:2069-2083. https://doi.org/10.13722/j.cnki.jrme.2019.0438 
Janiszewski M, Shen B, Rinne M (2019) Simulation of the interactions between hydraulic and natural fractures using a fracture mechanics approach. J Rock Mech Geotechn Eng 6:1138-1150. https://doi.org/10.1016/j.jrmge.2019.07.004

Liu S (2009) Research on cutting performance of shearer drum and cutting system dynamics. Dissertation, China University of Mining and Technology

Liu J, Liu F, Kong X (2008) Particle flow code numerical simulation particle breakage of rockfill. Geotechn Mech S1:107-112. https://doi.org/10.3969/j.issn.1000-7598.2008.z1.020

Liu S, Du C, Cui X et al (2009) Cutting experiment of the picks with different conicity and carbidetip diameters. J China Coal Soc 9:1276-1280. https://doi.org/10.13225/j.cnki.jccs.2009.09.016

Liu W, Wang X, Li C (2019a) Numerical study of damage evolution law of coal mine roadway by particle flow code (PFC) model. Geotechn Geol Eng 4:2883-2891. https://doi.org/10.1007/ s10706-019-00803-6

Liu S, Lu S, Wan Z et al (2019b) Investigation of the influence mechanism of rock damage on rock fragmentation and cutting performance by the discrete element method. R Soc Open Sci. https://doi.org/10.1098/rsos.190116

Mehranpour MH, Kulatilake PHSW (2017) Improvements for the smooth joint contact model of the particle flow code and its applications. Comput Geotech 87:163-177. https://doi.org/10. 1016/j.compgeo.2017.02.012

Qin D, Wang Z, Hu M et al (2015) Dynamic matching of optimal drum movement parameters of shearer based on multi-objective optimization. J China Coal Soc S2:532-539. https://doi.org/10. 13225/j.cnki.jccs.2015.0575

Shi HB, Xie JC, Wang XW, Li JL, Ge X (2020) An operation optimization method of a fully mechanized coal mining face based on semi-physical virtual simulation. Int J Coal Sci Technol 7(1):147-163

Sun Q, Wang G (2009) Introduction to the mechanics of particulate matter. Progress in Natural Sciences, Beijing
Tian W, Yang S, Huang Y (2018) Macro and micro mechanics behavior of granite after heat treatment by cluster model in particle flow code. Acta Mech Sin 1:175-186. https://doi.org/10. 1007/s10409-017-0714-3

Wang T, Zhou W, Chen J et al (2014a) Simulation of hydraulic fracturing using particle flow method and application in a coal mine. Int J Coal Geol 121:1-13. https://doi.org/10.1016/j.coal. 2013.10.012

Wang Y, Huang Z, Cui F (2014b) Damage evolution mechanism in the failure process of coal rock based on mesomechanics. J China Coal Soc 12:2390-2396. https://doi.org/10.13225/j.cnki. jecs.2014.0111

Wang J, Song SY, Li P (2020) An experimental research of dynamic characteristics for long wall shearer cutting unit gearbox in oblique cutting. Int J Coal Sci Technol 7(2):388-396

Wu J, Feng M, Mao X et al (2018) Particle size distribution of aggregate effects on mechanical and structural properties of cemented rockfill: experiments and modeling. Constr Build Mater 193:295-311. https://doi.org/10.1016/j.conbuildmat.2018. 10.208

Yang S, Tian W, Huang Y (2018) Failure mechanical behavior of preholed granite specimens after elevated temperature treatment by particle flow code. Geothermics 72:124-137. https://doi.org/10. 1016/j.geothermics.2017.10.018

Ye L, Yong T, Xiang L (2018) Stability analyses on slopes of clayrock mixtures using discrete element method. Eng Geol. https:// doi.org/10.1016/j.enggeo.2018.07.021

Zhao Z, Jing L, Neretnieks I (2012a) Particle mechanics model for the effects of shear on solute retardation coefficient in rock fractures. Int J Rock Mech Min Sci 52:92-102. https://doi.org/10.1016/j. ijrmms.2012.03.001

Zhao G, Dai B, Ma C (2012b) Study of Effects microparameters on macroproperties for parallel bonded model. Chin J Rock Mech Eng 7:1491-1498. https://doi.org/10.3969/j.issn.1000-6915. 2012.07.024 